\title{
An experimental study of the effect of clinker hardness on ball mill output and mathematical modelling of operational parameters using RSM method
}

\author{
S. Irudayaraj ${ }^{1 *}$, S. Charles ${ }^{2}$ \\ ${ }^{1}$ Shri Angalamman College of Engineering and Technology, Tiruchirappalli 621105, Tamilnadu, India \\ ${ }^{2}$ Dhanalakshmi Srinivasan College of Engineering, Coimbatore 641105, Tamilnadu, India
}

Received 12 July 2014, received in revised form 1 December 2014, accepted 1 December 2014

\begin{abstract}
One of the operational parameters in ball mill grinding process of composite cement is clinker hardness (litre weight of clinker). The quantity of fly ash to be blended in the composite cement is highly dependent on the clinker hardness. In this paper, the Response Surface Methodology (RSM) is used to formulate the experimental design and to analyze the effect of the operational parameters (input factors) such as clinker feed rate in tonnes per hour, fly ash feed rate in tonnes per hour and litre weight of clinker (clinker hardness) in grams/litre. The responses reported were mill output in tonnes per hour, cement residue in percentage, three days compressive strength in $\mathrm{kg} \mathrm{cm}^{-2}, 28$ days compressive strength in $\mathrm{kg} \mathrm{cm}^{-2}$, initial setting time and final setting time in minutes. The analysis using RSM revealed that in general the clinker hardness significantly affected the mill output. Mathematical models were developed to predict the responses.
\end{abstract}

K e y words: ball mill, fly ash, cement clinker, composite cement, response surface methodology

\section{Introduction}

Grinding processes are particularly energy consuming [1] in a cement industry since the energy consumption associated with grinding the raw materials and clinker in ball mills represents approximately $75 \%$ of the cement production costs. A ball mill is the equipment used for grinding the hard, nodular clinker from the cement kiln into the fine grey powder. Most types of cement are produced using the Portland clinker and the ball mills are widely used for the grinding process of Portland clinker. A ball mill is a horizontal cylinder partly filled with steel balls (or occasionally other shapes) that rotates on its axis, imparting a tumbling and cascading action on the balls present inside the mill. Material fed through the mill is crushed by impact and ground by attrition between the balls, also called grinding media. The smaller grades of grinding media are occasionally cylindrical rather than spherical. There exists a speed of rotation at which the con- tents of the mill would ride over the roof of the mill due to centrifugal action.

Ball mill grinding systems of cement manufacturing are either open circuit or closed circuit system [2]. Figure 1 presents the design of the grinding system (closed circuit), consisting of a two-chamber ball mill and the separators. The output achieved by a ball mill system varies according to the mill power, the fineness of the product and the hardness of the clinker. The litre weight of clinker, which is indirectly a measure of the clinker hardness [3], is an important factor that impacts the energy cost of the grinding process and it depends both on the clinker's mineral composition and its thermal history. The performance optimization of the ball mills is very much essential and will be possible only if the operational parameters of the ball milling process are known.

Michael Boulvin, Alain Vande Wouwer presented a nonlinear distributed parameter model of a grinding circuit used in the cement industry and on the basis

*Corresponding author: e-mail address: irudayaraj67@gmail.com 


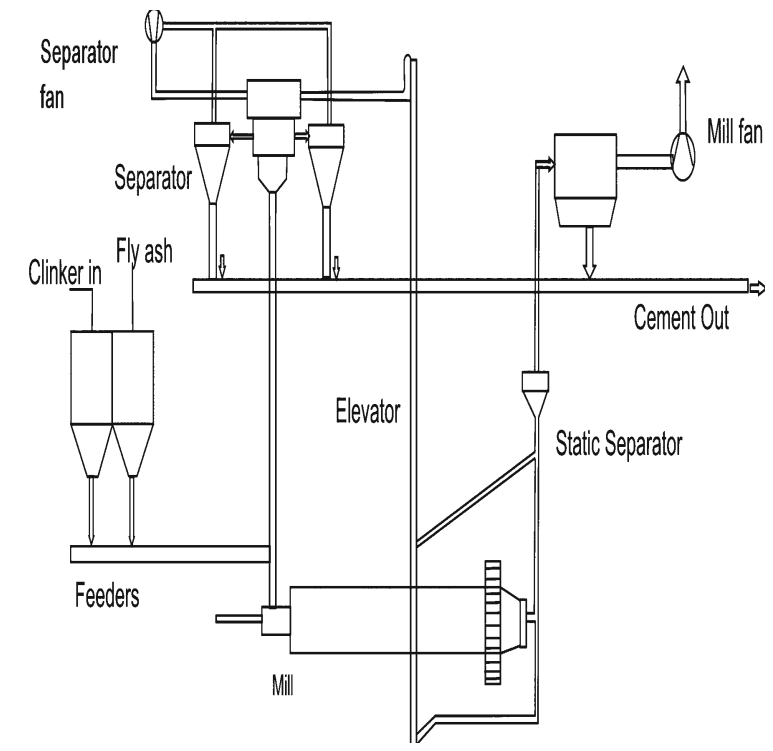

Fig. 1. Schematic layout of a ball mill grinding process of cement manufacturing.

of the experimental data collected on the real plant, a dynamic simulator was developed [1]. Hanifi Binici et al. [4] explored the capability of Genetic Expression Programming (GEP) in the prediction of heat of hydration of portland and blended cements. They have concluded that the proposed GEP models can be used as an important decision support mechanism to assist technicians in the prediction of heat of hydration of portland and blended cements. Cement Kiln Dust (CKD) produced in a cement production plant in Saudi Arabia along with fly ash resulting from combustion of heavy fuel oil in a local power generation plant were utilized by M. A. Daous [5] as waste material blends with portland cement, produced from the local plant, at various proportions. Bhatty [6] reported that due to the high lime content of CKD and subsequent ability to harden upon exposure to moisture, it is commonly used as a mixture with different solid-waste materials such as waste glass, fly ash, waste water sludge with the addition of cement [7]. The utilization of different classes of fly ash as a partial replacement of cement or aggregates in concrete mixes was investigated by many researchers in the last few years. It was reported that such utilization led to various technical, economical, and environmental benefits [8-10]. In this literature, it is seen that the study of the effect of clinker hardness on ball mill output and the mathematical modelling of operational parameters have not been attempted by the authors. Hence an initiative has been carried out in this research.

\section{Methodology}

The Response Surface Methodology (RSM) was de- veloped for reducing the number of experimental trials needed to evaluate multiple parameters and their interactions.

Response Surface Methodology [11] is a collection of statistical and mathematical methods useful for the modelling and analyzing the engineering problems. In this technique, the main objective is to optimize the response surface influenced by various operational parameters. Response Surface Methodology also quantifies the relationship between the controllable input parameters and the obtained response surfaces. The design procedure of RSM is as follows:

(i) Designing a series of experiments for adequate and reliable measurement of the response of interest.

(ii) Developing a mathematical model of the second order response surface with the best fittings.

(iii) Finding the optimal set of experimental parameters that produce the maximum or the minimum value of response.

(iv) Representing the effects of operational parameters through two or three dimensional plots.

If all variables are assumed to be measurable, the response surface can be expressed as follows:

$$
y=f\left(x_{1}, x_{2}, \ldots x_{k}\right) .
$$

It is assumed that the independent variables are continuous and controllable by experiments with negligible errors.

\section{Material and methods}

Fly ash is an artificial pozzolanic material, which is an inorganic residue obtained from the burning of pulverized coal and has cementitious properties, when mixed with cement is referred as composite cement. As it comes under hazardous waste material, the disposal is also a major problem. Henceforth this fly ash is used as an additive for many products and one of these products is composite cement. Class F fly ash was selected for this study and grinding was carried out in a commercial ball mill with two chamber end discharge ball mill of size $\varnothing 4.2 \mathrm{~m} \times 11.4 \mathrm{~m}$.

The objective of this research is to utilize the historical data design based on RSM for selecting the optimum set of input factors in a ball mill grinding process. The input factors selected were clinker feed rate, fly ash feed rate, litre weight of clinker. The input factors and their levels are shown in Table 1. The responses recorded were mill output, cement residue, 3 days compressive strength, 28 days compressive strength, initial setting time and final setting time [12]. The desirable range of the responses as per IS standards is shown in Table 2.

Historical data design based on RSM with 27 experimental runs [13] was chosen and the working 
Ta ble 1. Desirable range of input factors and levels

\begin{tabular}{|c|c|c|c|c|c|c|}
\hline \multirow{2}{*}{ Sl. No. } & \multirow{2}{*}{ Input factors } & \multirow{2}{*}{ Range } & \multirow{2}{*}{ Units } & \multicolumn{3}{|c|}{ Levels } \\
\hline & & & & 1 & 2 & 3 \\
\hline 1 & Clinker feed rate, $C$ & $52-60$ & tph & 52 & 56 & 60 \\
\hline 2 & Fly ash feed rate, $A$ & $16-24$ & tph & 16 & 20 & 24 \\
\hline 3 & Litre weight of clinker, $W$ & $1200-1400$ & $\mathrm{~g} \mathrm{l}^{-1}$ & 1200 & 1300 & 1400 \\
\hline
\end{tabular}

Table 2. Desirable range of responses

\begin{tabular}{clc}
\hline Sl. No. & Responses & Range \\
\hline 1 & Mill output, $O$ & $80-88$ tph \\
2 & Residue (fineness), $R$ & $2-6 \%$ \\
3 & 3 days compressive strength, $S 1$ & $230-260 \mathrm{~kg} \mathrm{~cm}^{-2}$ or $23-26 \mathrm{MPa}$ \\
4 & 28 days compressive strength, $S 2$ & $430-460 \mathrm{~kg} \mathrm{~cm}^{-2}$ or $43-46 \mathrm{MPa}$ \\
5 & Initial setting time, $T 1$ & Initial $\geq 60$ min \\
6 & Final setting time, $T 2$ & Final $\leq 600$ min \\
\hline
\end{tabular}

Table 3. Design matrix and the responses

\begin{tabular}{|c|c|c|c|c|c|c|c|c|c|}
\hline \multirow[b]{2}{*}{$\begin{array}{l}\text { Sl. } \\
\text { No. }\end{array}$} & \multicolumn{3}{|c|}{ Input Factors } & \multicolumn{6}{|c|}{ Responses } \\
\hline & $\begin{array}{l}\text { Level } \\
\text { of } C\end{array}$ & $\begin{array}{l}\text { Level } \\
\text { of } A\end{array}$ & $\begin{array}{l}\text { Level } \\
\text { of } W\end{array}$ & $\begin{array}{c}O \\
(\mathrm{tph})\end{array}$ & $\begin{array}{c}R \\
(\%)\end{array}$ & $\begin{array}{c}S 1 \\
\left(\mathrm{~kg} \mathrm{~cm}^{-2}\right)\end{array}$ & $\begin{array}{c}S 2 \\
\left(\mathrm{~kg} \mathrm{~cm}^{-2}\right)\end{array}$ & $\begin{array}{c}T 1 \\
(\min )\end{array}$ & $\begin{array}{c}T 2 \\
(\min )\end{array}$ \\
\hline 1 & 3 & 2 & 3 & 74 & 9.8 & 330 & 370 & 260 & 370 \\
\hline 2 & 1 & 1 & 2 & 72 & 3.2 & 270 & 640 & 200 & 285 \\
\hline 3 & 2 & 3 & 3 & 72 & 9.6 & 315 & 330 & 185 & 330 \\
\hline 4 & 1 & 1 & 3 & 72 & 9.8 & 335 & 385 & 285 & 375 \\
\hline 5 & 3 & 1 & 2 & 80 & 3.4 & 275 & 630 & 255 & 330 \\
\hline 6 & 1 & 2 & 1 & 76 & 2.2 & 175 & 400 & 130 & 250 \\
\hline 7 & 2 & 2 & 2 & 80 & 3.2 & 270 & 640 & 175 & 260 \\
\hline 8 & 1 & 3 & 1 & 80 & 1.8 & 170 & 390 & 100 & 235 \\
\hline 9 & 3 & 1 & 1 & 80 & 2.6 & 200 & 440 & 215 & 285 \\
\hline 10 & 2 & 1 & 3 & 73 & 9.8 & 340 & 380 & 305 & 385 \\
\hline 11 & 3 & 3 & 2 & 88 & 2.6 & 255 & 595 & 165 & 275 \\
\hline 12 & 2 & 2 & 1 & 80 & 2.2 & 180 & 410 & 155 & 255 \\
\hline 13 & 2 & 3 & 1 & 84 & 2.2 & 175 & 380 & 105 & 240 \\
\hline 14 & 1 & 3 & 2 & 80 & 2.4 & 245 & 590 & 150 & 265 \\
\hline 15 & 1 & 2 & 2 & 76 & 3.2 & 260 & 605 & 170 & 270 \\
\hline 16 & 2 & 2 & 3 & 73 & 9.6 & 325 & 370 & 245 & 255 \\
\hline 17 & 3 & 3 & 1 & 88 & 2.2 & 175 & 395 & 115 & 245 \\
\hline 18 & 1 & 1 & 1 & 72 & 2.4 & 190 & 425 & 175 & 270 \\
\hline 19 & 2 & 1 & 2 & 76 & 3.4 & 275 & 635 & 215 & 300 \\
\hline 20 & 2 & 3 & 2 & 84 & 2.8 & 250 & 590 & 155 & 265 \\
\hline 21 & 1 & 2 & 3 & 73 & 9.4 & 320 & 365 & 220 & 345 \\
\hline 22 & 1 & 3 & 3 & 75 & 9.2 & 315 & 340 & 285 & 375 \\
\hline 23 & 3 & 2 & 2 & 84 & 3.2 & 265 & 610 & 195 & 280 \\
\hline 24 & 3 & 2 & 1 & 84 & 2.4 & 185 & 415 & 160 & 265 \\
\hline 25 & 2 & 1 & 1 & 76 & 2.2 & 190 & 430 & 200 & 280 \\
\hline 26 & 3 & 3 & 3 & 74 & 9.4 & 320 & 350 & 195 & 340 \\
\hline 27 & 3 & 1 & 3 & 74 & 10.2 & 345 & 390 & 335 & 400 \\
\hline
\end{tabular}

ranges of the parameters were set at three levels.

Experiments were conducted according to the experimental design matrix using a pilot laboratory ball mill of size $\varnothing 500 \times 480 \mathrm{~mm}^{2}$ with an addition of a constant amount of $5 \%$ gypsum to increase the setting time. For each trial run the pilot mill was run for 40 
Ta b le 4. $R$-squared values of responses

\begin{tabular}{cccccc}
\hline \multicolumn{7}{c}{$R$-squared value } \\
\hline$O$ & $R$ & $S 1$ & $S 2$ & $T 1$ & $T 2$ \\
\hline 0.95120614 & 0.99835741 & 0.998438122 & 0.996159241 & 0.933888878 & 0.868144828 \\
\hline
\end{tabular}

Table 5. $P$-values for $O, R, S 1, S 2, T 1$, and $T 2$

\begin{tabular}{ccccccc}
\hline Source & $O$ & $R$ & $S 1$ & $S 2$ & $T 1$ & $T 2$ \\
\hline & Prob $>\mathrm{F}$ & Prob $>\mathrm{F}$ & Prob $>\mathrm{F}$ & Prob $>\mathrm{F}$ & Prob $>\mathrm{F}$ & Prob $>\mathrm{F}$ \\
\hline Model & $<0.0001$ & $<0.0001$ & $<0.0001$ & $<0.0001$ & $<0.0001$ & $<0.0001$ \\
$\mathrm{~A}$ & $<0.0001$ & 0.0072 & $<0.0001$ & 0.1524 & 0.0423 & 0.2247 \\
$\mathrm{~B}$ & $<0.0001$ & $<0.0001$ & $<0.0001$ & $<0.0001$ & $<0.0001$ & 0.0024 \\
$\mathrm{C}$ & $<0.0001$ & $<0.0001$ & $<0.0001$ & $<0.0001$ & $<0.0001$ & $<0.0001$ \\
$\mathrm{~A}^{2}$ & 0.5604 & 0.6371 & 0.6554 & 0.9382 & 0.3728 & 0.0692 \\
$\mathrm{~B}^{2}$ & 1.0000 & 0.3501 & 0.3763 & 0.3991 & 0.1398 & 0.0341 \\
$\mathrm{C}^{2}$ & $<0.0001$ & $<0.0001$ & $<0.0001$ & $<0.0001$ & 0.0434 & 0.0162 \\
$\mathrm{AB}$ & 0.5372 & 1.0000 & 0.6361 & 0.7427 & 0.0071 & 0.2157 \\
$\mathrm{AC}$ & 0.0002 & 0.7383 & 1.0000 & 0.6232 & 0.2213 & 0.7518 \\
$\mathrm{BC}$ & 0.0002 & 0.3225 & 0.3487 & 0.8695 & 0.8830 & 1.0000 \\
\hline
\end{tabular}

min duration and a total of 27 trial runs were carried out. A cube moulding machine was used to produce 54 cube samples of size $7.07 \times 7.07 \times 7.07 \mathrm{~cm}^{3}$ and the compressive strength was tested for 3 and 28 days cubes using compression testing machine. The fineness of cement was tested using the sieve analyzer. Initial and final setting time was measured by using the VICAT apparatus. The mill output was measured by electronic weighers. The design matrix and the responses are shown in Table 3.

\section{Regression analysis and mathematical model}

The response function representing any of the process parameters can be expressed as:

$Y=F(C, A, W)$, the relationship selected being a second degree response surface is expressed as follows:

$Y=b_{0}+b_{1} C+b_{2} A+b_{3} W+b_{11} C^{2}+b_{22} A^{2}+b_{33} W^{2}$

$+b_{12} C A+b_{13} C W+b_{23} A W$,

where $C$ is clinker feed rate (tph), $A$ is fly ash feed rate in (tph), and $W$ is litre weight of clinker $\left(\mathrm{gl}^{-1}\right)$.

Any mathematical model developed should be studied for both its direct and interaction effects of the variables on the responses. To determine the significant direct and interaction effects precisely, a statistical analysis software package, namely Design Expert 6.0.8 was used. The general mathematical model for the factors (based on ANOVA) was analyzed and the models [14] having the significant direct and interac- tion effects only with calculated regression coefficients are as follows:

$O=-898.00000+4.63194 C+7.52778 A+1.18167 W$ $+0.020833 C^{2}-3.33333 \times 10^{-4} W^{2}-0.015625 C A-$ $4.58333 \times 10^{-3} \mathrm{CW}-4.58333 \times 10^{-3} \mathrm{AW}$,

$R=436.31667+0.20972 C+0.26250 A-0.71683 \mathrm{~W}-$ $2.08333 \times 10^{-3} C^{2}-4.16667 \times 10^{-3} A^{2}+$ $2.90000 \times 10^{-4} W^{2}+4.16667 \times 10^{-5} \mathrm{CW}-$ $1.25000 \times 10^{-4} \mathrm{AW}$,

$S 1=-2204.81481+5.38194 C-1.38889 A+$ $2.86111 W-0.034722 C^{2}+0.069444 A^{2}-$

$8.05556 \times 10^{-4} W^{2}-0.026042 C A-$

$2.08333 \times 10^{-3} \mathrm{AW}$,

$S 2=-37783.28704+1.84028 C+0.59028 A$ $+59.26528 W+0.017361 C^{2}-0.19097 A^{2}-$ $0.022806 W^{2}+0.052083 C A-3.12500 \times 10^{-3} C W-$ $1.04167 \times 10^{-3} \mathrm{AW}$,

$T 1=1743.98148-3.68056 C+16.38889 A$ $-2.99444 W+0.45139 C^{2}+0.76389 A^{2}+$ $1.72222 \times 10^{-3} W^{2}-1.06771 C A-$ $0.017708 \times 10^{-3} C W+2.08333 \times 10^{-3} A W$,

$T 2=6823.24074-105.59028 C-28.33333 A$

$-5.59167 W+1.11111 C^{2}+1.31944 A^{2}+$

$2.44444 \times 10^{-3} W^{2}-0.52083 C A-$

$5.20833 \times 10^{-3} \mathrm{CW}$.

The model adequacy was examined through resid- 
DESIGN-EXPERT Plot O

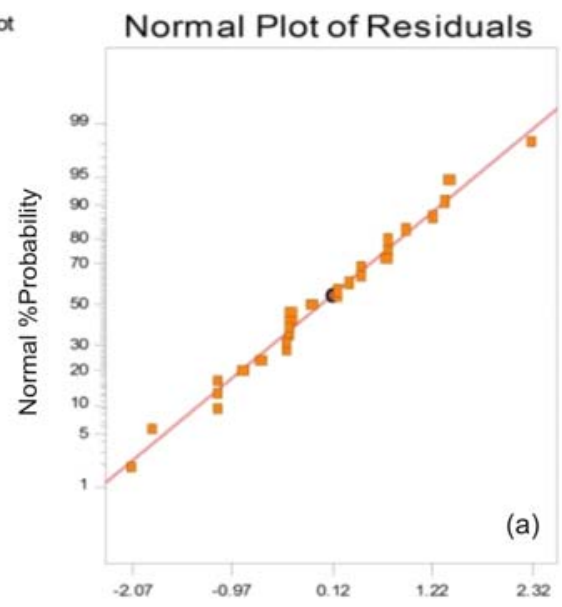

Studentized Residuals

DESIGN-EXPERT PIOt S1

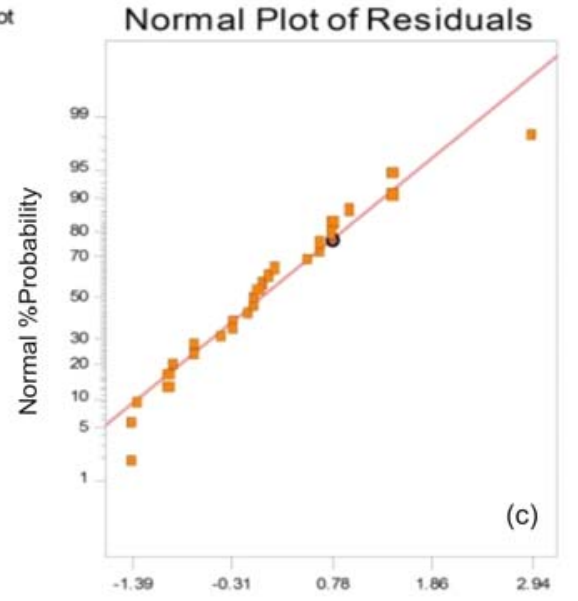

Studentized Residuals DESIGN-EXPERT PIot
T1

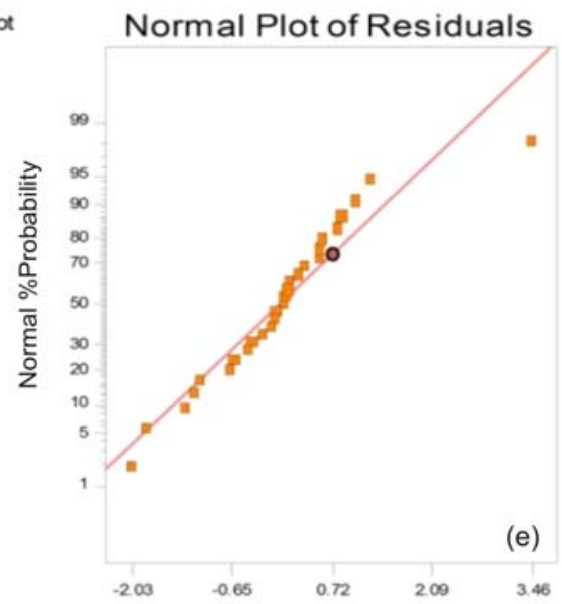

Studentized Residuals
DESIGN-EXPERT PIOt
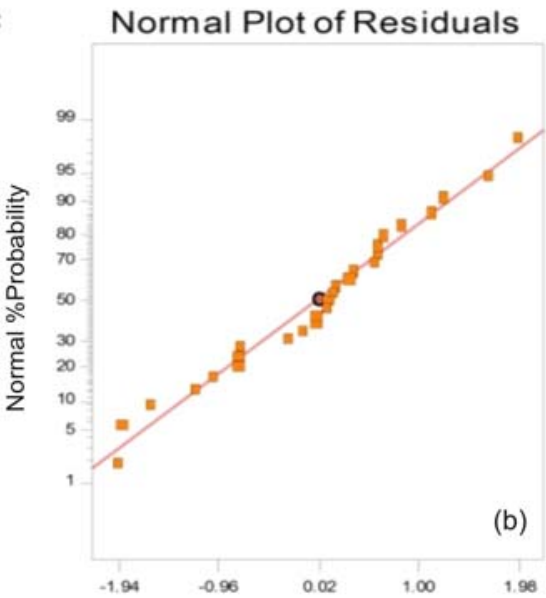

Studentized Residuals

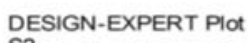

S2

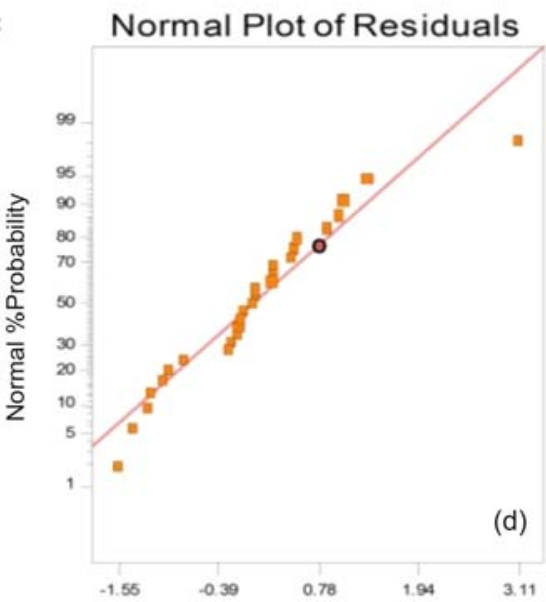

Studentized Residuals
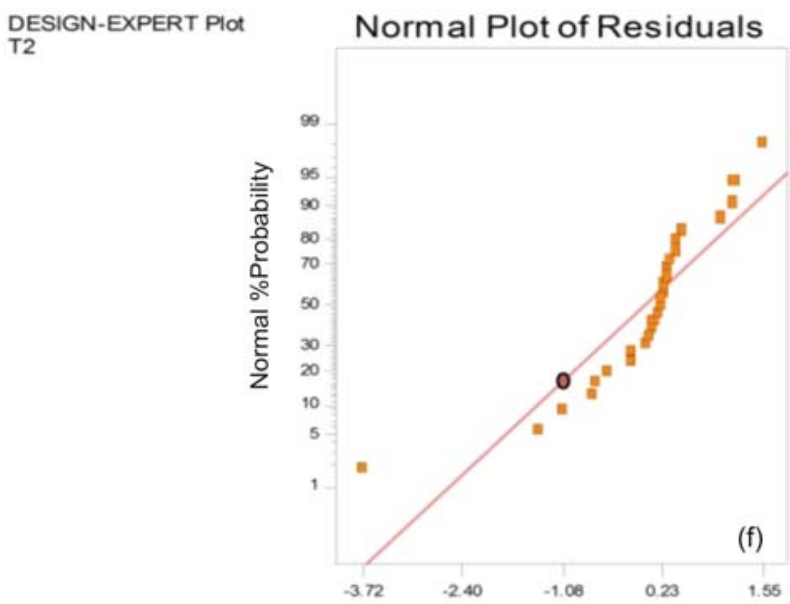

Studentized Residuals

Fig. 2a-f. Normal probability plots of residuals. 
Table 6. Optimal solution of RSM

\begin{tabular}{ccccccccc}
\hline$C$ & $A$ & $W$ & $O$ & $R$ & $S 1$ & $S 2$ & $T 1$ & $T 2$ \\
\hline 56.33 & 24 & 1301.33 & 82.6975 & 2.8369 & 253.647 & 591.832 & 145.546 & 258.023 \\
\hline
\end{tabular}

Table 7. Software predicted responses and actual experimental results

\begin{tabular}{lcccccc}
\hline & $O$ & $R$ & $S 1$ & $S 2$ & $T 1$ & $T 2$ \\
\hline Predicted responses by software & 82.6975 & 2.8369 & 253.647 & 591.832 & 145.546 & 258.023 \\
Actual experimental value & 80 & 2.6 & 250 & 595 & 141 & 260 \\
\hline
\end{tabular}

DESIGN-EXPERT Plot

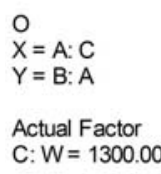

C: $W=1300.00$

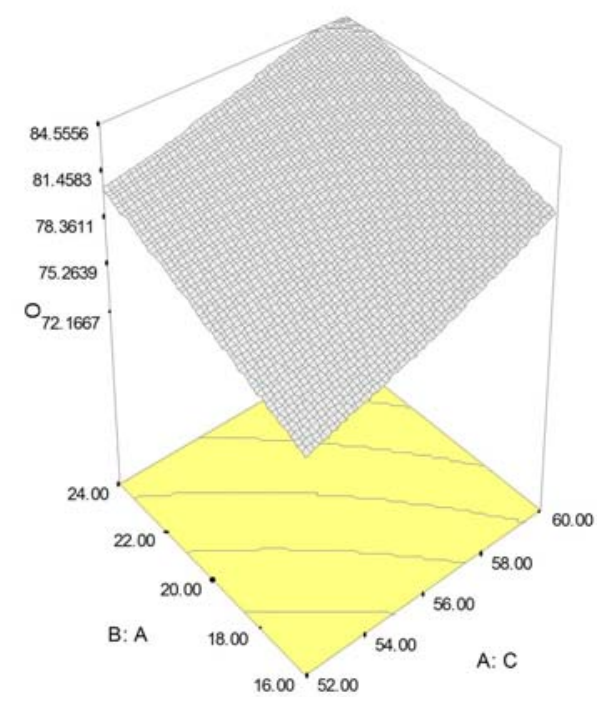

Fig. 3. Main and interaction effects of clinker feed rate, fly ash feed rate on mill output

ual analysis. Figures $2 \mathrm{a}-\mathrm{f}$ show the normal probability plots of the residuals indicating that the responses are legitimate.

An analysis of variance (ANOVA) was used to calculate the regression coefficients and to check the significance of the models developed. Table 4 shows the $R$-squared values of the responses. The $P$-values of the responses are shown in Table 5 and the optimal solution of the RSM is shown in Table 6 .

\section{Confirmation experiments}

Confirmation experiments were conducted at the optimal settings of the operational parameters and the results obtained from the experiments were compared with the predicted responses as shown in Table 7 . The experimental responses were found to be significantly
DESIGN-EXPERT Plot

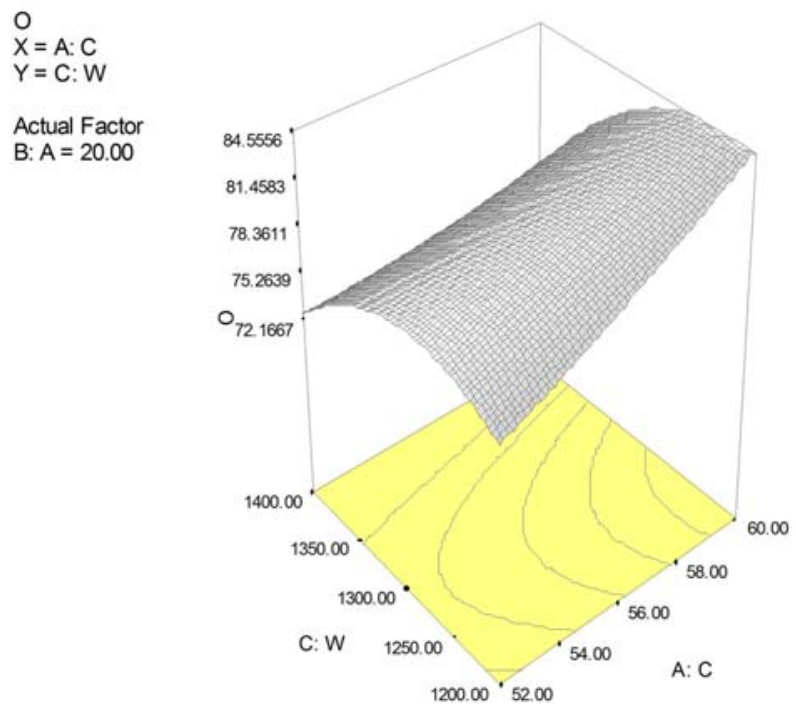

Fig. 4. Main and interaction effects of clinker feed rate, litre weight of clinker (clinker hardness) on mill output.

close to the predicted responses, confirming the adequacy.

\section{Results and discussion}

Figures $3-5$ show the main effects and the interaction effects of clinker feed rate, fly ash feed rate and litre weight of clinker on mill output.

Figure 3 shows that the mill output increases with the increase in clinker and fly ash feed rate. This is due to the fact that grindability of the mill is not affected by the feed rate within the experimental region.

Figure 4 shows that the mill output increases with the increase of clinker feed rate and litre weight of clinker whereas it decreases with further increase in clinker feed rate and litre weight of clinker. Thus, it is evident that the output of the mill suffers due to the increase in clinker hardness. 


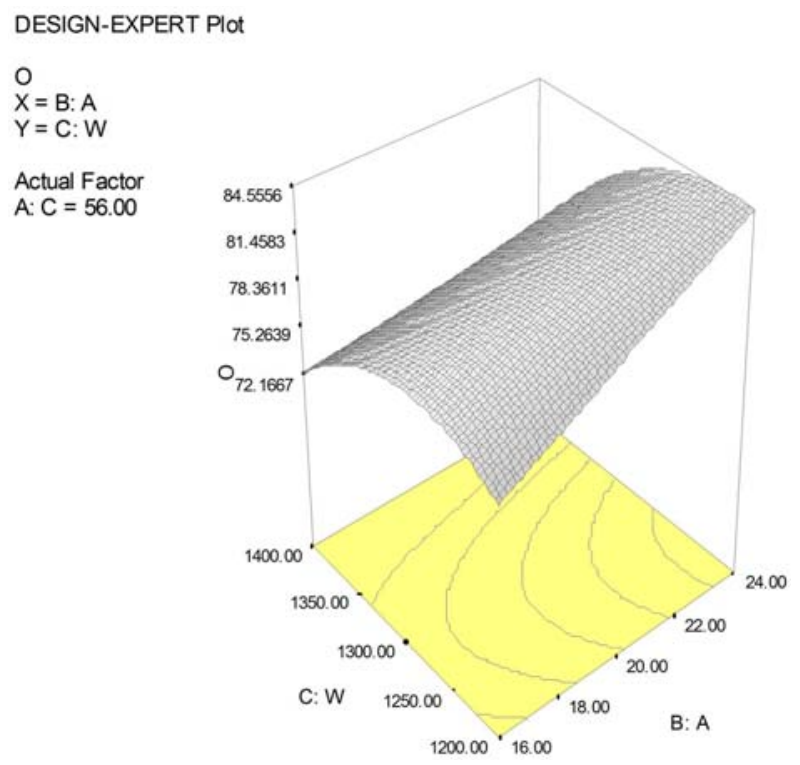

Fig. 5. Main and interaction effects of fly ash feed rate, litre weight of clinker (clinker hardness) on mill output.

Figure 5 shows that the mill output increases with the increase of fly ash feed rate and litre weight of clinker whereas it decreases with further increase in fly feed rate and litre weight of clinker. This is also due to the increase in litre weight of clinker which is an indicator of clinker hardness.

\section{Conclusions}

The following conclusions are derived from this experimental research work:

1. The effect of clinker hardness on the mill output was investigated and RSM technique was adopted to optimize the addition of fly ash and the litre weight of clinker in ball mill cement grinding process.

2 . The optimum value for the litre weight of clinker was found to be $1301.33 \mathrm{~g} \mathrm{l}^{-1}$. Above this the 28 day compressive strength and the mill output decreases.

3 . The optimum value for addition of fly ash was found to be $24 \mathrm{tph}$. Above this the compressive strength of cement decreases.
4. This research work would be useful in increasing the productivity of the ball mill in cement industry and would aid in conservation of limestone resources. The models can be used as a quick decision making tool in cement industry for predicting the responses.

\section{References}

[1] Boulvin, M., Wouwer, A. V., Lepore, R.: IEEE Transactions on Control Systems Technology, 11, 2003, p. 715. doi:10.1109/TCST.2003.816406

[2] Mumuni, I. I., Dagadu, C. P. K., Danso, K. A., Adu, P. S., Affum, H. A., Lawson, I., Appiah, G. K., Coleman, A., Addo, M. A.: Research Journal of Applied Sciences, Engineering and Technology, 3, 2011, p. 26.

[3] Topalov, A. V., Kaynak, O.: Journal of Process Control., 14, 2004, p. 581. doi:10.1016/j.jprocont.2003.10.005

[4] Binici, H., Kayadelen, C., Cagatay, I. H., Tokyay, M., Kaplan, H.: Scientific Research and Essay, 4, 2009, p. 141.

[5] Daous, M. A.: JKAU: Eng. Sci., 15, 2004, p. 47.

[6] Bhatty, J. I.: Alternative Uses of Cement Kiln Dust, RP 327. Skokie, Illinois, USA, Portland Cement Association 1995.

[7] Bhatty, M. S. Y.: Use of Kiln Dust in Blended Cements. PCA R\&D Serial No. 1717. Skokie, Illinois, USA, Portland Cement Association 1983.

[8] Papadakis, V. G.: Cement and Concrete Research, 29, 1999, p. 1727. doi:10.1016/S0008-8846(99)00153-2

[9] Erdogdu, K., Turker, P.: Cement and Concrete Research, 28, 1998, p. 1217. doi:10.1016/S0008-8846(98)00116-1

[10] Bouzoubaa, N., Zhang, M. H., Malhotra, V. M.: Cement and Concrete Research, 30, 2001, p. 1393. doi:10.1016/S0008-8846(01)00592-0

[11] Montgomery, D. C.: Design and Analysis of Experiments. New York, John Wiley 1991.

[12] Bentz, D. P., Hansen, A. S., Guynn, J. M.: Cement \& Concrete Composites, 33, 2011, p. 824. doi:10.1016/j.cemconcomp.2011.04.008

[13] Amiri, M., Najafi, A. A., Gheshlaghi, K.: Journal of Applied Sciences, 8, 2008, p. 2732. doi:10.3923/jas.2008.2732.2738

[14] Charles, S., Arunachalam, V. P., Balasubramanian, R.: Journal of Advanced Materials, 38, 2006, p. 25. 